Article

\title{
Suitability of a Coupled Hydrodynamic Water Quality Model to Predict Changes in Water Quality from Altered Meteorological Boundary Conditions
}

\author{
Leon van der Linden *, Robert I. Daly and Mike D. Burch \\ South Australian Water Corporation, Adelaide, SA 5000, Australia; \\ E-Mails: rob.daly@sawater.com.au (R.I.D.); mike.burch@sawater.com.au (M.D.B.) \\ * Author to whom correspondence should be addressed; E-Mail: leon.vanderlinden@sawater.com.au; \\ Tel.: +61-8-7424-2108; Fax: +61-8-7003-2108.
}

Academic Editor: Julia Piantadosi

Received: 30 May 2014 / Accepted: 12 January 2015 / Published: 20 January 2015

\begin{abstract}
Downscaled climate scenarios can be used to inform management decisions on investment in infrastructure or alternative water sources within water supply systems. Appropriate models of the system components, such as catchments, rivers, lakes and reservoirs, are required. The climatic sensitivity of the coupled hydrodynamic water quality model ELCOM-CAEDYM was investigated, by incrementally altering boundary conditions, to determine its suitability for evaluating climate change impacts. A series of simulations were run with altered boundary condition inputs for the reservoir. Air and inflowing water temperature (TEMP), wind speed (WIND) and reservoir inflow and outflow volumes (FLOW) were altered to investigate the sensitivity of these key drivers over relevant domains. The simulated water quality variables responded in broadly plausible ways to the altered boundary conditions; sensitivity of the simulated cyanobacteria population to increases in temperature was similar to published values. However the negative response of total chlorophyll- $a$ suggested by the model was not supported by an empirical analysis of climatic sensitivity. This study demonstrated that ELCOM-CAEDYM is sensitive to climate drivers and may be suitable for use in climate impact studies. It is recommended that the influence of structural and parameter derived uncertainty on the results be evaluated. Important factors in determining phytoplankton growth were identified and the importance of inflowing water quality was emphasized.
\end{abstract}


Keywords: water quality; sensitivity; ELCOM-CAEDYM

\section{Introduction}

The Goyder Water Research Institute project C.1.1 was initiated to fill a gap in the current understanding of the potential impacts of climate change on South Australia. The project seeks to understand climate drivers, downscale global circulation (GCM) model projections of future climate and develop a suite of model applications for the evaluation of climate change impacts on society. Current global circulation model (GCM) projections suggest Australian average temperatures will increase by 1.0 to 5.0 degrees by 2070 (compared to 1980-1999), there will be a decrease in average annual rainfall over southern Australia and there will be an increase in the number of hot days and warm nights [1]. Decreases in winter and autumn wind speed and increases in spring and winter downward solar radiation are also projected, but these projections are subject to large uncertainties [2]. Recent efforts to downscale GCM outputs to the catchment scale have identified the potential for reduced catchment yields as the result of reduced precipitation, changes in rainfall seasonality and increased temperatures [3-5]. Besides issues of water quantity, there are potential impacts of climate change on water quality [6,7]. Reservoirs play a major role in determining the water quality within a given water supply system, as they act as both barriers to (e.g., pathogens) and producers of (e.g., cyanobacteria (toxins, tastes and odors), iron and manganese) water quality hazards [8]. Reservoirs integrate the prevailing hydrology, meteorology, biology and biogeochemistry and the resulting quantity and quality of water is a valuable resource that requires sound management to ensure the utility and sustainability of the source water; water quality models are tools to this end.

The potential impacts of climate change on water quality has been evaluated using integrated modeling schemes which include water quality models [9-13]. Such schemes use a combination of catchment and lake/reservoir models that use meteorological boundary conditions as inputs. The meteorological conditions are altered to represent projected future climate and the resulting simulations are taken to represent the potential impacts of those changed climatic conditions. Too few of these studies have been performed to make generalizations about the potential impacts; both positive and negative influences have been identified. Additionally, the differences in model structure and method make it difficult to compare the different studies directly. There are many sources of uncertainty within such a modeling scheme, including the choice of GCM, emissions scenario, downscaling methodology, and the selection of and rigor of application of the hydrological, constituent and lake/reservoir water quality models, including model structure selection and identification of parameters. Each step in the modeling scheme needs to be thoroughly evaluated to ensure the results can be useful.

It is therefore appropriate to adequately test the response of the proposed reservoir water quality model to changes in the environmental variables expected to change in the future. Formalizing our understanding of the way that water quality variables respond to climate related model inputs is fundamentally important to understanding the outputs we generate from models [13]. As these models will be used to project the impacts of downscaled climate scenarios, it is important that the response of the water quality models to the boundary conditions is understood. Water quality models vary in their 
data input requirements and often contain options for the sub-model structures they contain, making it difficult to assume that they will be equally sensitive in any given application. Responses of chemical and biological processes to the changes in physical state generated by changes in meteorological inputs are dynamic and interactive and therefore difficult to resolve without resolving individual sensitivities in an explicit analysis.

The outputs from any model are dependent on the inputs. It follows that uncertainty in the inputs, either the boundary conditions or the model parameters, contributes to the uncertainty of the model results. Quantification of the influence of the inputs on the model outputs is known as sensitivity analysis and has been extensively described in the literature. Complex models with many parameters, boundary conditions and long runtimes have particular challenges associated with the analysis of their sensitivity and uncertainty. Consequently a great deal of effort has gone towards developing screening methods to identify sensitive parameters and evaluate their influence on model output [14-17]. Less often the influence of boundary conditions or input data is evaluated. Generally, the error associated with these inputs is considered to be less than the uncertainty associated with model parameters as they are quantities that are generally measured at, or proximal to, the lake or reservoir being modeled, using accurate instrumentation. However the range of meteorological boundary conditions are expected to change in the future [18] and given the non-linear and non-monotonic nature of ecosystem models, their behavior in these conditions is uncertain. As suitable observed validation data cannot exist for unobserved future conditions, model behavior under altered boundary conditions can only be validated against qualitative projected responses of ecosystems. These qualitative responses may be derived from space-for-time approaches, robust ecophysiological conceptual models and response data [19] and ensemble model predictions [20].

Therefore, the goal of this work is to answer the question: Does ELCOM-CAEDYM demonstrate appropriate climatic sensitivity to be used as part of a robust integrated modeling scheme? The responsiveness of the ELCOM-CAEDYM model [21,22] to changes in meteorological boundary conditions was analyzed. A previous application of the model to Happy Valley Reservoir (HVR) was used in conjunction with scenarios with altered environmental forcing of incremental changes in flow, air and water temperature, and wind speed. Responses in water quality variables of primary focus were cyanobacteria and soluble metals; further consideration was given to water temperature and water column stratification due to their important role in determining mixing and the rates of biogeochemical reactions. This work does not constitute a model sensitivity analysis, sensu stricto, but evaluates the climatic sensitivity or responsiveness of ELCOM-CAEDYM and compares it to other studies and an empirical climate sensitivity analysis of chlorophyll- $a$ in Happy Valley Reservoir.

\section{Materials and Methods}

\subsection{Happy Valley Reservoir}

Happy Valley Reservoir ( $\left.35^{\circ} 04^{\prime} 12^{\prime \prime} \mathrm{S}, 138^{\circ} 34^{\prime} 12^{\prime \prime} \mathrm{E}\right)$ is situated to the south of Adelaide, the capital of South Australia (Figure 1). It was created by the construction of an earth wall dam between 1892 and 1897. Following a rehabilitation project from 2002 to 2004, it has a capacity of 11,600 ML, a surface area of 178 hectares and average and maximum depths of 6.5 and $18 \mathrm{~m}$, respectively. It is an 
off stream reservoir and supplies raw water to South Australia's largest water treatment plant, which produces up to $400 \mathrm{ML}$ of filtered water per day, resulting in a hydraulic retention time of 15-30 days. As HVR is isolated from its natural catchment, it is supplied with water from the Onkaparinga River system via an aqueduct from Clarendon Weir, which is in turn supplied from the much larger Mount Bold Reservoir (3507'12" S, 138 42'00" E). Mount Bold Reservoir collects water from the Mount Lofty Ranges and is supplemented with water pumped from the River Murray, as are most of South Australia's reservoirs. Happy Valley Reservoir has experienced a range of water quality challenges in the past, with blue-green algae (cyanobacteria) causing taste and odor problems in recent decades. The use of artificial destratification (mixing) and algaecides are used for management in the reservoir, while granular activated carbon used in the water treatment process to reduce taste and odor compound concentrations to acceptable levels in the product water. As HVR is supplied with water from an unprotected catchment (i.e., containing various farming activities and human habitation), vigilance against pathogens is required and loads of nutrients are greater than is generally desirable. During the study period, nutrient concentrations were, total phosphorus, $0.05-0.1 \mathrm{mgL}^{-1}$; total Kjeldahl nitrogen, 0.5-1.0 $\mathrm{mgL}^{-1}$; filterable reactive phosphorus, $0.005-0.03 \mathrm{mgL}^{-1}$; ammonia, $0.005-0.05 \mathrm{mgL}^{-1}$ and oxidized nitrogen, $0.05-0.5 \mathrm{mgL}^{-1}$. The seasonal temperature range is generally between $8-10{ }^{\circ} \mathrm{C}$ and $25-27{ }^{\circ} \mathrm{C}$, strong persistent stratification is prevented from occurring by the operation of a bubble plume aerator. Due to the importance of Happy Valley Reservoir to Adelaide's water supply, the South Australian Water Corporation has invested heavily in monitoring and research into the processes influencing water quality.

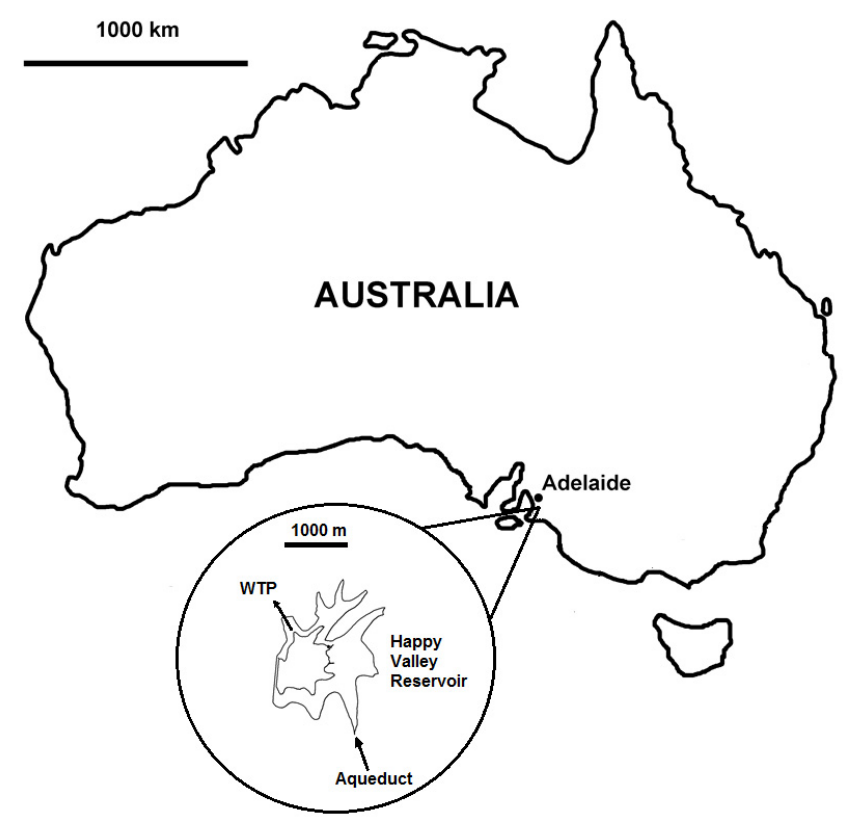

Figure 1. Location of Happy Valley Reservoir. Inset shows $10 \mathrm{~m}$ contours of depth and inflow from the aqueduct and the location of the offtake to the water treatment plant (WTP).

\subsection{Model Description}

The Estuary and Lake Computer Model (ELCOM) is a hydrodynamic model that simulates the temporal behavior of stratified water bodies with environmental forcing. The model solves the 
unsteady, viscous Navier-Stokes equations for incompressible flow using the hydrostatic assumption for pressure. The simulated processes include baroclinic and barotropic responses, rotational effects, tidal forcing, wind stresses, surface thermal forcing, inflows, outflows, and transport of salt, heat and passive scalars [21]. When coupled with the Computational Aquatic Ecosystem DYnamics Model [22] water quality model, ELCOM can be used to simulate three-dimensional transport and interactions of flow physics, biology and chemistry. ELCOM uses the Euler-Lagrange method for advection of momentum with a conjugate-gradient solution for the free-surface height. Passive and active scalars (i.e., tracers, salinity and temperature) are advected using a conservative ULTIMATE QUICKEST discretization, see [21] and references within for further details.

The Centre for Water Research was previously engaged to apply ELCOM-CAEDYM to Happy Valley Reservoir [23]. Upon delivery, the model was considered appropriate for the simulation of water movement, contaminant transport, algal growth and biogeochemical cycling [23]. ELCOM was applied at three resolutions (25,50 and $100 \mathrm{~m}$ grid sizes); the finest grid to be used for examining short-circuiting and inflow dilution, and the coarser grids for quicker runtimes and running scenarios relating to stratification, algal growth and soluble metal release from sediments (the $100 \mathrm{~m}$ grid was used in this study). The hydrodynamic model was validated against temperature sensor data over two periods, 29 June-6 October 2005 and 23 October 2005-8 February 2006. The parameter set for CAEDYM was derived from applications to other Australian reservoirs and some minor calibration of parameters to suit Happy Valley Reservoir. The manual calibration focused on parameters that could not be derived from literature values and included, the density of particulate organic matter, the maximum rate for microbial decomposition of particulate organic phosphorus (nitrogen), the maximum rate of mineralization of dissolved organic phosphorus (nitrogen), the dissolved oxygen $1 / 2$ saturation constant for nitrification, the rate of denitrification and the phosphorus $1 / 2$ saturation constant for algal uptake. Some deficiencies in the calibration of the algal growth components of the model remained.

Two algal groups were included in the model structure, representing chlorophytes (green algae) and cyanophytes (blue-green algae). The phytoplankton growth model was parameterized according to literature values, with only a single parameter being manually calibrated for Happy Valley Reservoir (Table 1). Parameters relating to light, temperature, phosphorus uptake and respiratory losses were different between the two phytoplankton groups. All other parameters were shared and derived from literature values. Notably, buoyancy regulation by cyanobacteria was not invoked in the model structure.

Table 1. Phytoplankton group parameters that differentiate the response to ecophysiological drivers in the ELCOM-CAEDYM model set up.

\begin{tabular}{ccccc}
\hline Parameter & $\begin{array}{c}\text { Cyanophyte } \\
\text { Value }\end{array}$ & $\begin{array}{c}\text { Chlorophyte } \\
\text { Value }\end{array}$ & Description & Reference \\
\hline$\mu_{\mathrm{GTH}}$ & 0.8 & 1.2 & Maximum growth rate $\left(\mathrm{d}^{-1}\right)$ & {$[24]$} \\
$\vartheta_{\mathrm{Ag}}$ & 1.09 & 1.07 & Temperature multiplier for growth $(-)$ & {$[25,26]$} \\
$\mu_{\mathrm{RES}}$ & 0.09 & 0.10 & Respiration, mortality and excretion $\left(\mathrm{d}^{-1}\right)$ & {$[27]$} \\
$\mathrm{K}_{\mathrm{P}}$ & 0.009 & 0.008 & $\mathrm{P} 1 / 2$ saturation constant $\left(\mathrm{mg} \mathrm{L}^{-1}\right)$ & Calibrated \\
$\mathrm{I}_{\mathrm{K}}$ & 130 & 100 & Light $1 / 2$ saturation constant $\left(\mu \mathrm{E} \mathrm{m}^{-2} \mathrm{~s}^{-1}\right)$ & {$[28]$} \\
$\mathrm{T}_{\mathrm{STD}}$ & 24 & 20 & Standard temperature for algal growth $\left({ }^{\circ} \mathrm{C}\right)$ & {$[29]$} \\
$\mathrm{T}_{\mathrm{OPT}}$ & 30 & 22 & Optimum temperature for algal growth $\left({ }^{\circ} \mathrm{C}\right)$ & {$[29,30]$} \\
$\mathrm{T}_{\mathrm{MAX}}$ & 39 & 35 & Maximum temperature for algal growth $\left({ }^{\circ} \mathrm{C}\right)$ & {$[29]$} \\
\hline
\end{tabular}


For this work, the model was not further calibrated or modified beyond the work of Romero et al. [23] and therefore no performance metrics are presented. The lack of extensive calibration to HVR water quality dynamics means the results of the study can be considered to be a general test of the response sensitivity of ELCOM-CAEDYM to climate drivers and not an investigation of the likely effects of climate change on water quality in Happy Valley Reservoir.

\subsection{Scenarios for Analysis of ELCOM-CAEDYM Climatic Sensitivity}

A series of twenty four (24) scenarios were defined, synthetic input data files were generated and ELCOM-CAEDYM simulations were run. As stratification, algal growth and soluble metal concentrations were of key interest, the summer period simulation was used. The $100 \mathrm{~m}$ grid version of ELCOM was used to minimize the runtime required, as short-circuiting was not a primary concern of the water quality problems being investigated. The input boundary conditions analyzed were selected to represent the "climate drivers" of precipitation, air temperature and wind speed and are represented by the input files as changes in flow, air and water temperature, and wind speed, respectively (these will be referred to as INFLOW, WIND and TEMP in text). The synthetic input files were generated by applying a linear multiplier, for INFLOW and WIND, and an increment in the case of TEMP (Table 2). Temperature was modified in this fashion to facilitate comparison to potential temperature change magnitudes. For comparison, -5 and +5 degrees correspond to multipliers of 0.8 and 1.25 , respectively, at 20 degrees Celsius, similar to the average temperature in the reservoir during the simulations. As ELCOM-CAEDYM will fail if changes to the water budget result in violations in the boundary conditions, changes in the inflow and outflow must be balanced, therefore the outflow (consumption at the offtake) was increased by a corresponding amount. The FLOW scenarios could therefore be considered to represent a change in the consumption of water by the water treatment plant (WTP), rather than changes in precipitation, strictly. This may initially seem artificial; however, as HVR is an offline storage and the inflow to the reservoir is fully regulated by a flume at Clarendon Weir, it can be interpreted as representing changes in demand, especially as a summer period was considered.

Table 2. Boundary condition modifications applied in the sensitivity analysis. A scenario was generated for each change in meteorological variable, resulting in 24 scenarios differing from the base scenario.

\begin{tabular}{ccc}
\hline $\begin{array}{c}\text { Temperature (TEMP) } \\
\text { [Increment] }\end{array}$ & $\begin{array}{c}\text { Precipitation (FLOW) } \\
\text { [Multiplier] }\end{array}$ & $\begin{array}{c}\text { Wind Speed (WIND) } \\
\text { [Multiplier] }\end{array}$ \\
\hline-5.0 & 0.50 & 0.50 \\
-2.0 & 0.75 & 0.75 \\
-1.0 & 0.90 & 0.90 \\
-0.5 & 0.95 & 0.95 \\
0.5 & 1.05 & 1.05 \\
1.0 & 1.10 & 1.10 \\
2.0 & 1.25 & 1.25 \\
5.0 & 1.50 & 1.50 \\
\hline
\end{tabular}


The scenarios were run using the same initial conditions; a "spin-up" period of 1 week was excluded from all summary calculations. As potable water production is the focus of the study, water quality (temperature, suspended solids, chlorophyll, iron and manganese) at the reservoir offtake was analyzed, along with "whole of reservoir" characteristics, such as water temperature and $g^{\prime}$ (the reduced gravity due to stratification, [21]). Changes in water quality were evaluated as changes in the mean concentration, the maximum concentration and the period of the simulation that the concentration was above a threshold value (green algal and cyanobacterial chlorophyll only, 1 and $10 \mu \mathrm{g} / \mathrm{L}$, respectively). In order to facilitate the interpretation of the phytoplankton dynamics, summaries of the state variables governing the growth of the two species modeled were calculated as means of the time series values.

\subsection{An Empirical Analysis of the Climatic Sensitivity of Chlorophyll-a to Temperature}

Historical records of chlorophyll- $a$ and water temperature were collated from the primary reservoir surface monitoring location for the period 1998 to 2013. Monthly medians and anomalies were calculated for water temperature and chlorophyll- $a$ concentration. The monthly anomalies were normalized to unity, so as to be able to compare directly to modeling results summarized with a similar method. Linear regressions were fitted to the raw anomalies and normalized values, both for the entire year and for the summer months only.

\section{Results and Discussion}

\subsection{Lake Physical Characteristics}

The (modeled) physical properties of the lake were altered by the changes in boundary conditions. The degree of stratification, as indicated by average $g^{\prime}$, was altered in all scenarios; changes in wind speed had a strong negative effect on lake stratification (Table 3). Increasing air and inflowing water temperature resulted in increased reservoir stratification, as did increased flow. Water temperature in the reservoir was not strongly influenced by the INFLOW scenarios, however the WIND and TEMP scenarios had strong effects on the mean of the average, minimum and maximum water temperatures observed over the simulations (Table 3). Only small impacts on reservoir volume and level were observed (not shown).

\subsection{Water Quality}

An increase in average modeled cyanobacterial chlorophyll was observed with elevated temperature (Figure 2a). The average concentration of reduced soluble iron (FeII) also increased with temperature while soluble manganese was less responsive (Figure 2). Sensitivity responses were close to linear near the origin $( \pm 10 \%)$, but some became non-linear at the extremes of the scenarios investigated. Exceedance of the threshold selected for cyanobacterial chlorophyll increased approximately linearly with increasing temperature above that of the original scenario, but had little effect below that level (data not shown). The FLOW scenarios had a consistently linear influence on reservoir water quality; increasing average concentrations of chlorophyte and cyanobacterial chlorophyll, MnII and FeII were observed in simulations with reduced flow; only the average concentration of suspended solids 
(SSOL1) decreased with decreasing flow (Figure 2b). Changes in maximum modeled values behaved similarly as did duration of exceedance for the chlorophyll variables (not shown).

Table 3. Summary of average physical properties for climatic sensitivity analysis of ELCOM-CAEDYM simulations of Happy Valley Reservoir.

\begin{tabular}{cccccc}
\hline Factor & $\begin{array}{c}\text { Increment/ } \\
\text { Multiplier }\end{array}$ & $\mathbf{g}^{\prime}\left(\mathbf{s}^{2}\right)$ & $\begin{array}{c}\text { Temperature } \\
\text { Mean }\left({ }^{\circ} \mathbf{C}\right)\end{array}$ & $\begin{array}{c}\text { Temperature } \\
\text { Max }\left({ }^{\circ} \mathbf{C}\right)\end{array}$ & $\begin{array}{c}\text { Temperature } \\
\text { Min }\left({ }^{\circ} \mathbf{C}\right)\end{array}$ \\
\hline Original & - & 0.0502 & 20.5 & 21.8 & 16.5 \\
INFLOW & 0.50 & 0.0481 & 20.9 & 22.2 & 16.6 \\
INFLOW & 0.75 & 0.0490 & 20.8 & 22.0 & 16.6 \\
INFLOW & 0.90 & 0.0496 & 20.6 & 21.9 & 16.5 \\
INFLOW & 0.95 & 0.0498 & 20.6 & 21.9 & 16.5 \\
INFLOW & 1.05 & 0.0503 & 20.5 & 21.8 & 16.5 \\
INFLOW & 1.10 & 0.0505 & 20.5 & 21.8 & 16.6 \\
INFLOW & 1.25 & 0.0510 & 20.3 & 21.7 & 16.6 \\
INFLOW & 1.50 & 0.0513 & 20.2 & 21.5 & 16.6 \\
TEMP & -5.0 & 0.0454 & 17.0 & 18.3 & 13.4 \\
TEMP & -2.0 & 0.0481 & 19.1 & 20.4 & 15.9 \\
TEMP & -1.0 & 0.0490 & 19.8 & 21.1 & 16.2 \\
TEMP & -0.5 & 0.0495 & 20.2 & 21.5 & 16.4 \\
TEMP & +0.5 & 0.0505 & 20.9 & 22.2 & 16.7 \\
TEMP & +1.0 & 0.0511 & 21.3 & 22.5 & 17.0 \\
TEMP & +2.0 & 0.0524 & 22.0 & 23.2 & 17.3 \\
TEMP & +5.0 & 0.0571 & 24.1 & 25.4 & 17.5 \\
WIND & 0.50 & 0.0984 & 22.7 & 25.9 & 17.0 \\
WIND & 0.75 & 0.0681 & 21.5 & 23.4 & 17.0 \\
WIND & 0.90 & 0.0560 & 20.9 & 22.4 & 16.7 \\
WIND & 0.95 & 0.0528 & 20.7 & 22.1 & 16.6 \\
WIND & 1.05 & 0.0474 & 20.4 & 21.6 & 16.6 \\
WIND & 1.10 & 0.0452 & 20.2 & 21.4 & 17.2 \\
WIND & 1.25 & 0.0397 & 19.8 & 20.8 & 17.4 \\
WIND & 1.50 & 0.0334 & 19.3 & 20.1 & 17.3 \\
\hline & & & & &
\end{tabular}

The relationship between WIND and algal growth was obviously non-linear with large increases in the average concentrations of both algal groups with decreasing wind speed (Figure 2c). Cyanobacteria were especially favored by low wind speeds. Reduction of wind speed from $90 \%$ to $75 \%$ of today's averages resulted in a large increase in the duration of exceedance by cyanobacteria (not shown). The simulated phytoplankton production rates were low $\left(\sim 0.1\right.$ day $\left.^{-1}\right)$ compared to what they can potentially be $\left(\sim 0.3-0.5 \mathrm{day}^{-1}\right)$ and probably are in HVR. This was also noted by Romero et al. [23]. The simulated whole lake averages of respiration exceeded that of production in cyanobacteria, indicating that they were limited to growing in a limited volume of the lake where sufficient light was available. Elevated temperatures increased cyanobacterial production rates but these increased production rates were kept in check by elevated respiration. There was very little change in the nutrient (N\&P) limitation of phytoplankton, even under the INFLOW scenarios; simulated phytoplankton growth was more limited by light availability (Table 4). 
(a)

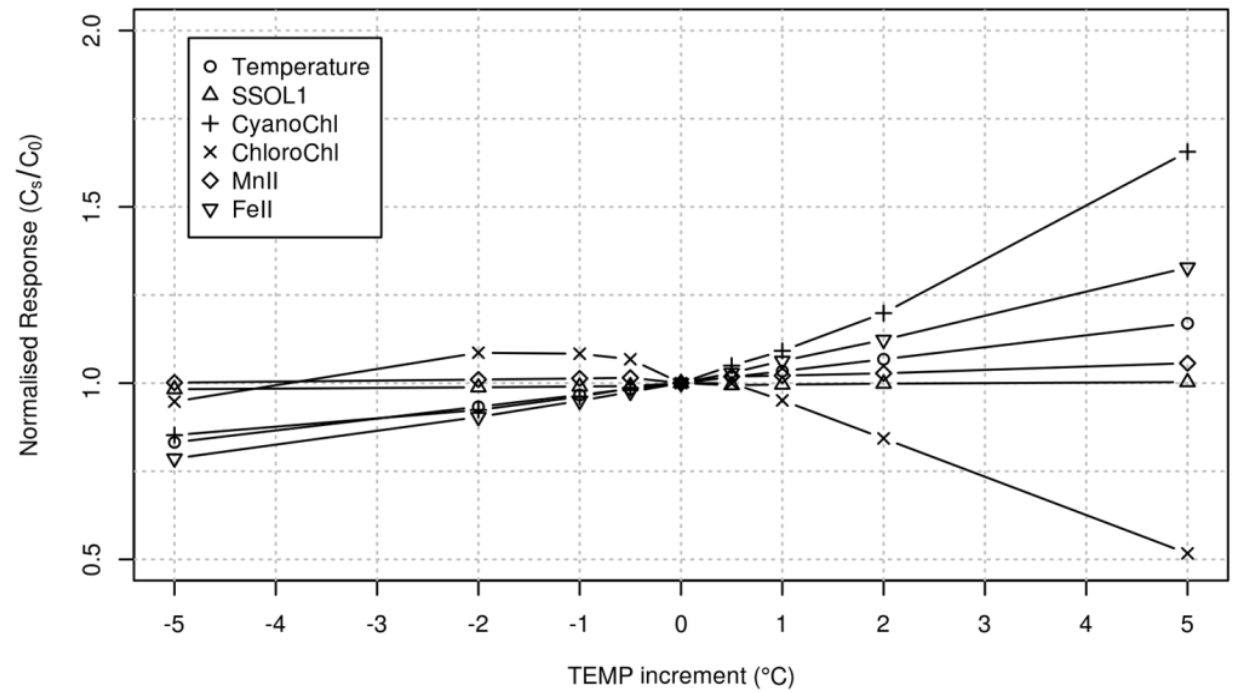

(b)

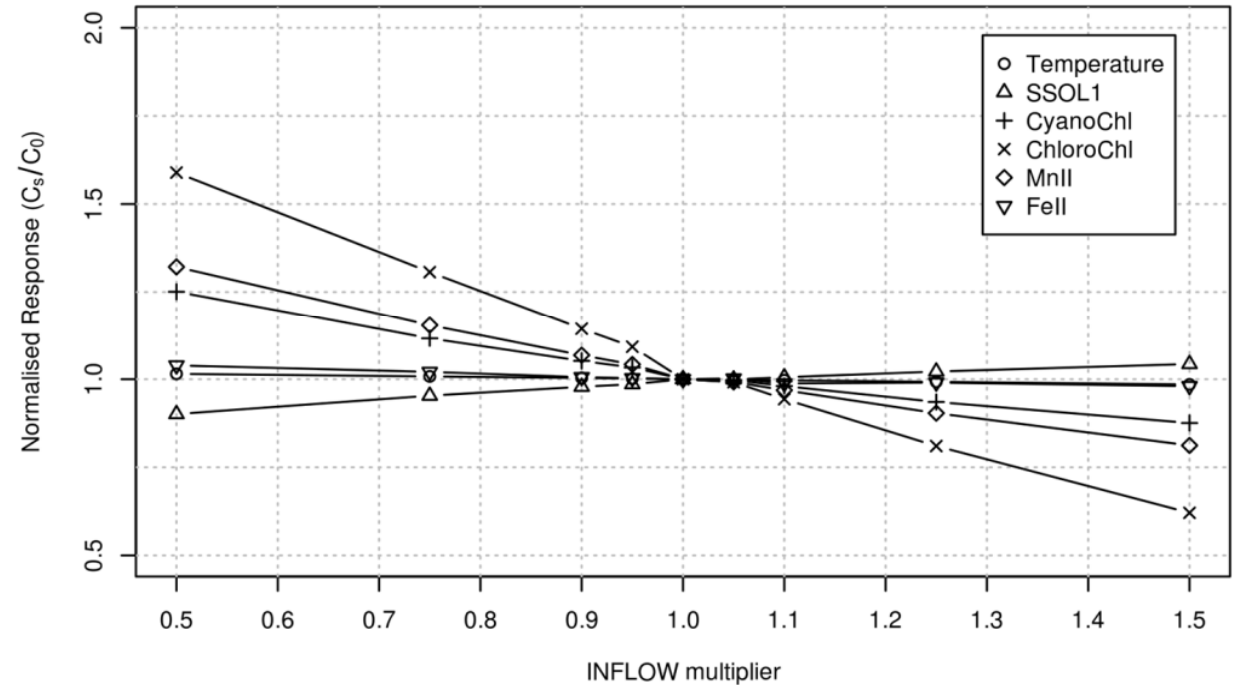

(c)

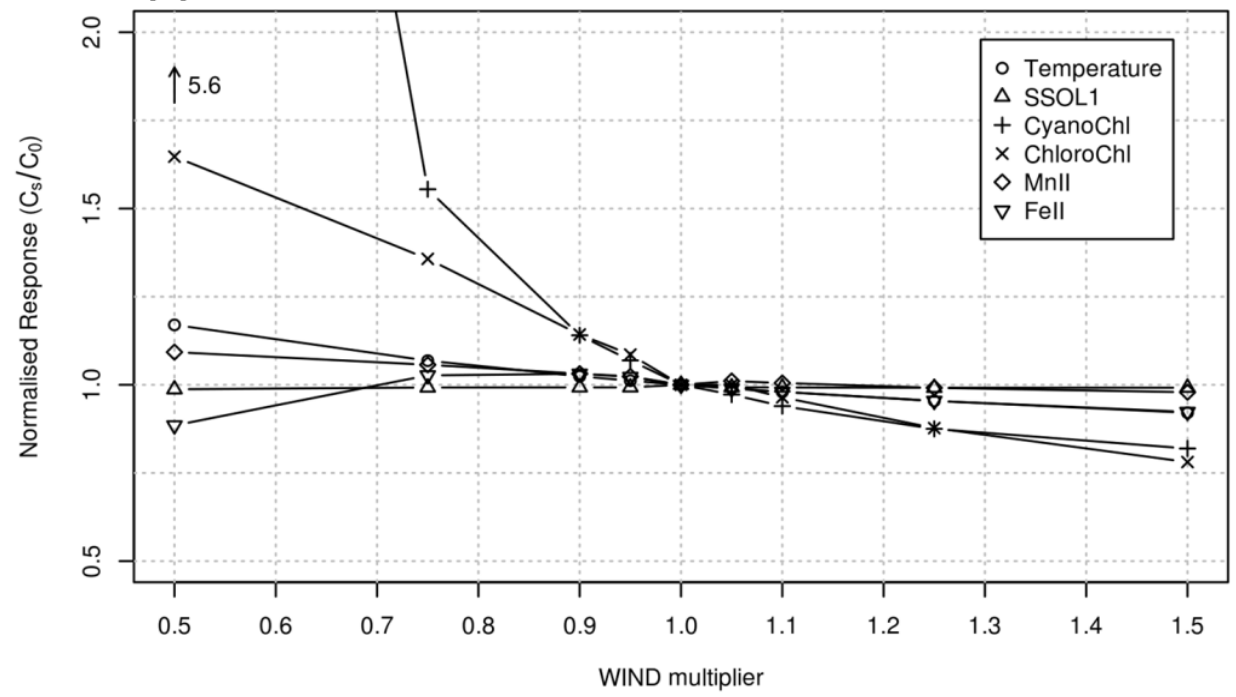

Figure 2. Change in mean modeled water quality values over the summer period in the different sensitivity analysis scenarios where temperature (a); rate of inflow and outflow (b) or wind speed (c) were incrementally changed. 
Table 4. Mean cyanobacterial growth characteristics in ELCOM-CAEDYM simulations. The "Limitation by" values indicate the degree of growth limitation by light, phosphorus and nitrogen. It takes a value from 0 to 1 ; where 1 is unlimited and 0 is completely limited (no growth).

\begin{tabular}{cccccc}
\hline \multirow{2}{*}{ Scenario } & Production & Respiration & \multicolumn{3}{c}{ Limitation by } \\
\cline { 2 - 5 } & $\left(\mathbf{d a y}^{-1}\right)$ & $\left(\mathbf{d a y}^{-1}\right)$ & Light & Phosphorus & Nitrogen \\
\hline Original & 0.080 & 0.093 & 0.099 & 0.915 & 0.890 \\
INFLOW by 0.5 & 0.079 & 0.096 & 0.095 & 0.916 & 0.883 \\
INFLOW by 1.5 & 0.081 & 0.091 & 0.102 & 0.916 & 0.890 \\
TEMP by -5 & 0.061 & 0.076 & 0.101 & 0.917 & 0.890 \\
TEMP by +5 & 0.108 & 0.115 & 0.106 & 0.909 & 0.884 \\
WIND by 0.5 & 0.083 & 0.106 & 0.086 & 0.923 & 0.899 \\
WIND by 1.5 & 0.075 & 0.087 & 0.103 & 0.917 & 0.889 \\
\hline
\end{tabular}

\subsection{Implied Model Climatic Sensitivity}

These scenarios demonstrate that ELCOM-CAEDYM is responsive to changes in environmental drivers that are expected to change under future climate. The model tested was not heavily calibrated and therefore the results are able to be generalized. The observed sensitivities are consistent with qualitative expectations on the basis of contemporary understanding of reservoir processes; for example, that increased temperature and stratification may; increase the prevalence of cyanobacteria; and result in longer periods of decreased dissolved oxygen concentration and higher dissolved metal concentration. Other authors have observed model climatic sensitivities that resulted in increases in the proportion of cyanobacteria by $1 \%-7.8 \%$ per $1{ }^{\circ} \mathrm{C}$ increase in temperature (using the model PROTECH [31]). From a review of the literature of the potential impact of climate on phytoplankton communities, Elliott [13] concluded that projected future climate would result in increased relative abundance of cyanobacteria and changes in the phenology of phytoplankton dynamics but not necessarily an increase in the seasonal amount of phytoplankton biomass. These conclusions are consistent with the responses observed in this study.

Important interactions with nutrient availability exist [32] but this was not investigated here. As an independent factor, nutrient addition (sensu INFLOW scenarios) did not have a large effect on the phytoplankton dynamics, presumably because of the lack of nutrient limitation (Table 4). The model tested in this study employed a relatively simple representation of phytoplankton community dynamics; only two main functional groups were represented. Furthermore some physiological mechanisms that facilitate cyanobacterial dominance, despite being available in CAEDYM, were not used in the model application of Romero et al. [23]. Greater sensitivity and/or more non-linearity may be expected if these mechanisms (e.g., buoyancy regulation) were implemented.

The environmental drivers that were manipulated in the scenarios were not investigated factorially, however they are not completely independent; changes in mean and maximum water temperature occurred in the INFLOW and WIND scenarios (Table 3). This complicates the interpretation of model outputs without extensive comparison of individual simulations; an effort not warranted by the goals of this study. The scenarios were arbitrarily selected to quickly develop a picture of the sensitivity of the model to changed boundary conditions. As such, the important environmental drivers of dilution and 
nutrient loading are confounded in the multiplication of inflow volumes. Inflow scenarios assumed the same constituent concentrations and therefore the higher flow scenarios had higher nutrient loads. However as chlorophyll concentrations decreased as flow increased; it is apparent that dilution was a more important driver of algal biomass than nutrient load and availability. Despite this, the prediction that phytoplankton growth is rarely limited by nutrient availability may suggest that reducing the external load may be an option for reducing algal growth. The internal load was not investigated as part of this study but given the short water retention time of the reservoir, it is probably of minor importance, compared to the external load. The reduction of nutrient availability represents a potential strategy for adaptation to climate change and the likely negative effects on water quality resulting from increased cyanobacterial growth. Water quality models, such as ELCOM-CAEDYM, have an important role to play in determining the potential benefit of a nutrient reduction program.

\subsection{Empirical Reservoir Climatic Sensitivity}

Linear regression between water temperature and chlorophyll median monthly anomalies did not resolve slope estimates significantly different from zero $(0.105 \pm 0.134, \operatorname{Pr}(>|t|)=0.43)$. The weak positive slope estimate combined with a poor predictive relationship $\left(R^{2}=0.0142\right)$ demonstrates that surface water temperature did not play an important role in determining total chlorophyll in this period (Figure 3b); it also demonstrates that total chlorophyll was not negatively correlated with water temperature, as implied by the water quality model (Figure 3a). This might suggest that deficiencies in definition of model structure or parameter identification have resulted in a non-behavioral model response (one not consistent with our expectations). These deficiencies could, for example, be found in the parameterization of the temperature response functions for growth, or be the product of the over-simplification of the phytoplankton community. This remains speculative, as this simple comparison cannot resolve the differences between the processes structuring algal growth in the model scenarios as compared to those operating over a longer period and in different years, within the reservoir. It must further be noted that the empirical analysis is limited to (monthly) anomalies less than $+2{ }^{\circ} \mathrm{C}$ and so could not explore the full range of (annual) anomalies as defined by the model scenarios.

(a)

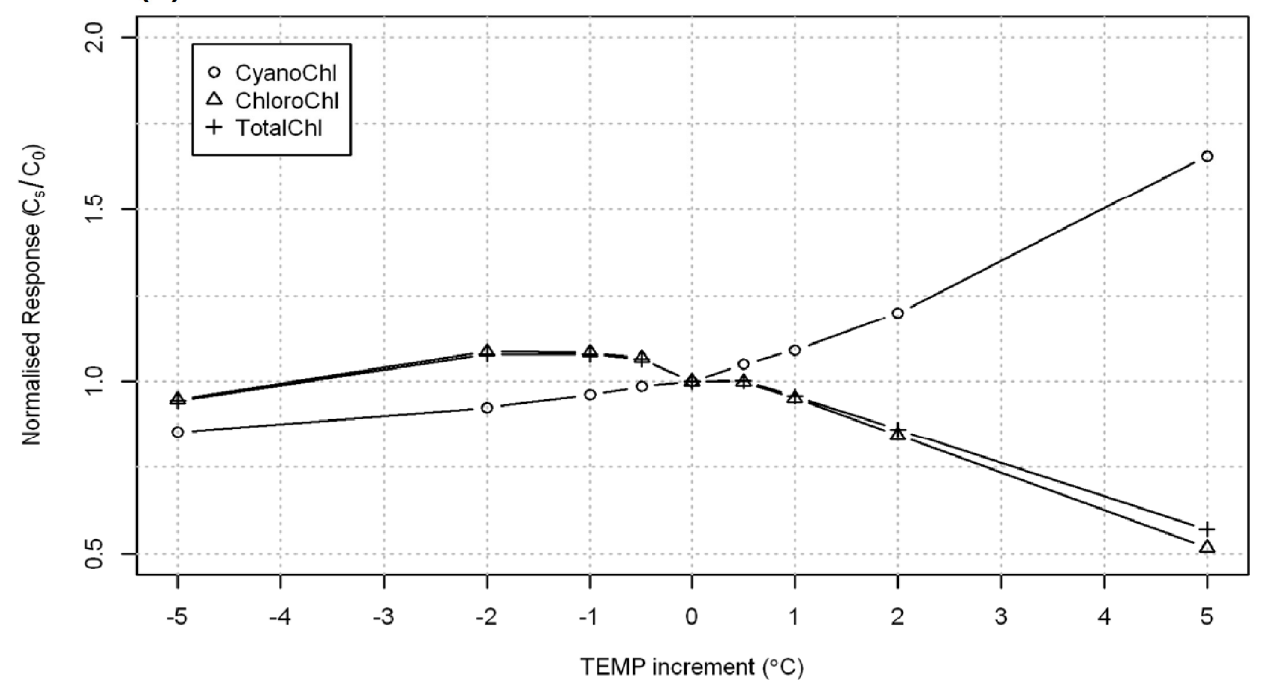

Figure 3. Cont. 


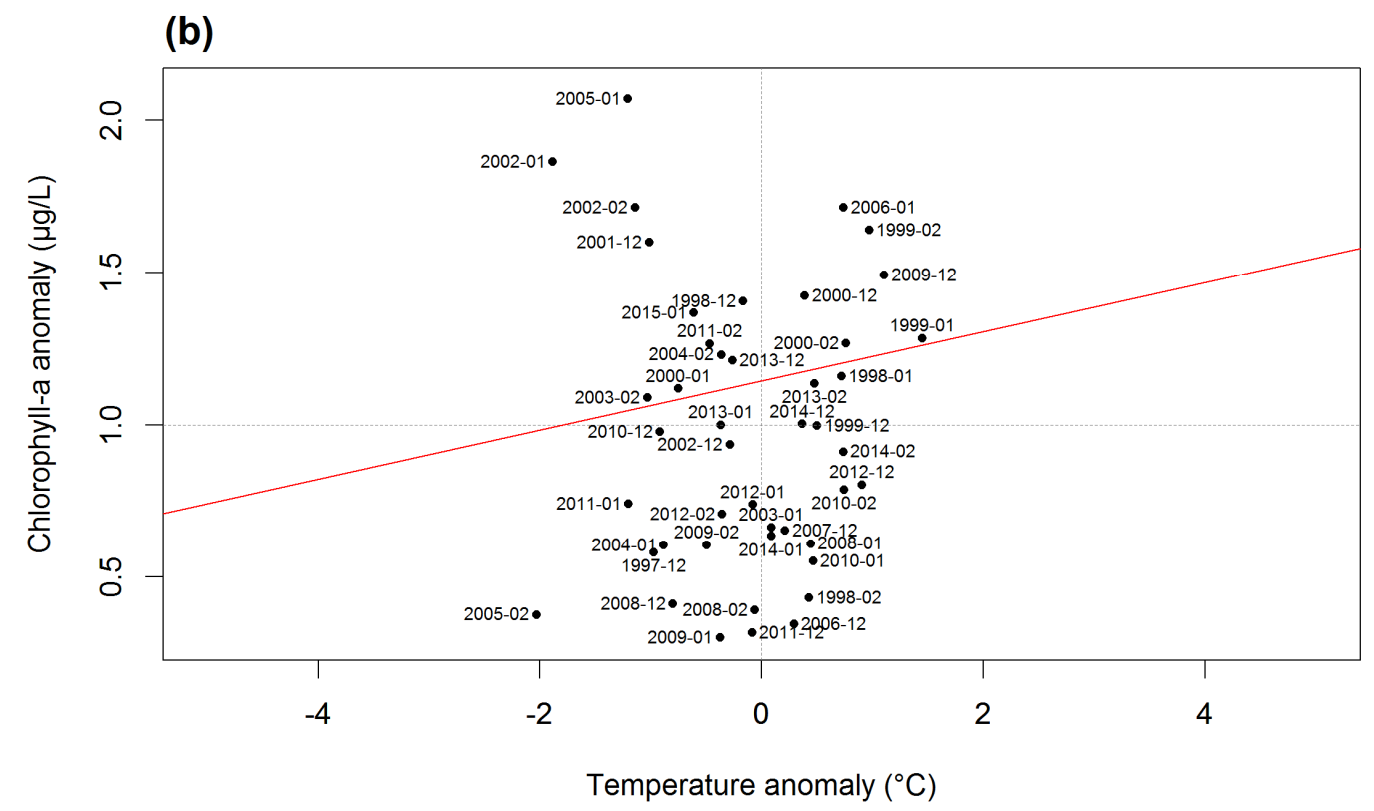

Figure 3. Comparison of (a) model derived climate sensitivity to (b) empirical reservoir climate sensitivity of chlorophyll- $a$ to temperature in summer (December, January, February). In panel (b) each point represents the unity normalized anomaly from the monthly median value calculated over the period 1998-2013 and is labeled as yyyy-mm.

\section{Conclusions}

This study demonstrated that ELCOM-CAEDYM is sensitive to climate drivers and suitable for use in climate impact studies. Rigorous evaluation of the impact of selection of model structures and parameter values on the conclusions drawn from scenarios conducted with altered boundary conditions is advised. This study highlighted factors likely to be important in determining phytoplankton growth in Happy Valley Reservoir. Further it demonstrates that the water quality of the source waters will be of major importance to the reservoir water quality dynamics.

\section{Acknowledgments}

This work was funded by the Goyder Water Research Institute Project C1.1. Development of an agreed set of climate projections for South Australia.

\section{Author Contributions}

Leon van der Linden conceived and implemented the model climatic sensitivity analysis, the empirical climate sensitivity analysis, analysed the data, interpreted the results and prepared the manuscript; Robert Daly prepared the original input data for ELCOM-CAEDYM and contributed to interpreting the results and preparing the manuscript; Mike Burch conceived the work program, secured funding, managed the research group, and contributed to preparing the manuscript.

\section{Conflicts of Interest}

The authors declare no conflict of interest. 


\section{References}

1. CSIRO. State of the Climate 2012; CSIRO and Bureau of Meteorology: Canberra, Australia, 2012; p. 12.

2. CSIRO. Climate Change in Australia; CSIRO: Canberra, Australia, 2007.

3. Heneker, T.; Cresswell, D. Potential Impact on Water Resource Availability in the Mount Lofty Ranges due to Climate Change; Science, Monitoring and Information Division, Department for Water: Adelaide, Australia, 2010.

4. Charles, S.P.; Heneker, T.; Bates, B.C. Stochastically downscaled rainfall projections and modelled hydrological response for the Mount Lofty Ranges, South Australia. In Proceedings of Water Down Under 2008, Adelaide, Australia, 15-18 April 2008; Lambert, M., Daniell, T., Leonard, M., Eds.; Engineers Australia: Adelaide, Australia, 2008; pp. 428-438.

5. Green, G.; Gibbs, M.; Wood, C. Impacts of Climate Change on Water Resources, Phase 3: Northern and Yorke Natural Resources Management Region DFW Technical Report 2011/03; Government of South Australia, Department for Water: Adelaide, Australia, 2011; Volume 1.

6. Whitehead, P.G.; Wilby, R.L.; Battarbee, R.W.; Kernan, M.; Wade, A.J. A review of the potential impacts of climate change on surface water quality. Hydrol. Sci. J. 2009, 54, 101-123.

7. Delpla, I.; Jung, A.-V.; Baures, E.; Clement, M.; Thomas, O. Impacts of climate change on surface water quality in relation to drinking water production. Environ. Int. 2009, 35, 1225-1233.

8. Brookes, J.; Burch, M.; Hipsey, M.; Linden, L.; Antenucci, J.; Steffensen, D.; Hobson, P.; Thorne, O.; Lewis, D.; Rinck-Pfeiffer, S.; et al. A Practical Guide to Reservoir Management; Cooperative Research Centre for Water Quality and Treatment: Adelaide, Australia, 2008; p. 116.

9. Arheimer, B.; Andréasson, J.; Fogelberg, S.; Johnsson, H.; Pers, C.B.; Persson, K. Climate change impact on water quality: Model results from southern Sweden. Ambio 2005, 34, 559-566.

10. Mimikou, M.A.; Baltas, E.; Varanou, E.; Pantazis, K. Regional impacts of climate change on water resources quantity and quality indicators. J. Hydrol. 2000, 234, 95-109.

11. Saloranta, T.; Forsius, M.; Järvinen, M.; Arvola, L. Impacts of projected climate change on the thermodynamics of a shallow and a deep lake in Finland: Model simulations and Bayesian uncertainty analysis. Hydrol. Res. 2009, 40, 234-248.

12. Thorne, O.M.; Fenner, R.A. Modelling the impacts of climate change on a water treatment plant in South Australia. Water Sci. Technol. Water Supply 2008, 8, 305-312.

13. Elliott, J.A. Is the future blue-green? A review of the current model predictions of how climate change could affect pelagic freshwater cyanobacteria. Water Res. 2012, 46, 1364-1371.

14. Arhonditsis, G.B.; Perhar, G.; Zhang, W.; Massos, E.; Shi, M.; Das, A. Addressing equifinality and uncertainty in eutrophication models. Water Resour. Res. 2008, 44, doi:10.1029/2007WR005862.

15. Makler-Pick, V.; Gal, G.; Gorfine, M.; Hipsey, M.R.; Carmel, Y. Sensitivity analysis for complex ecological models-A new approach. Environ. Model. Softw. 2011, 26, 124-134.

16. Saltelli, A. Making best use of model evaluations to compute sensitivity indices. Comput. Phys. Commun. 2002, 145, 280-297.

17. Campolongo, F.; Cariboni, J.; Saltelli, A. An effective screening design for sensitivity analysis of large models. Environ. Model. Softw. 2007, 22, 1509-1518. 
18. Schlabing, D.; Frassl, M.A.; Eder, M.M.; Rinke, K.; Bárdossy, A. Use of a weather generator for simulating climate change effects on ecosystems: A case study on Lake Constance. Environ. Model. Softw. 2014, 61, 326-338.

19. Paerl, H.W.; Paul, V.J. Climate change: Links to global expansion of harmful cyanobacteria. Water Res. 2012, 46, 1349-1363.

20. Trolle, D.; Hamilton, D.P.; Pilditch, C.A.; Duggan, I.C.; Jeppesen, E. Predicting the effects of climate change on trophic status of three morphologically varying lakes: Implications for lake restoration and management. Environ. Model. Softw. 2011, 26, 354-370.

21. Hodges, B.; Dallimore, C. Estuary, Lake and Coastal Ocean Model: ELCOM v2.2 User Manual; Centre for Water Research, University of Western Australia: Crawley, Australia, 2007.

22. Hipsey, M.R.; Romero, J.R.; Antenucci, J.P.; Hamilton, D.P. Computational Aquatic Ecosystem Dynamics Model CAEDYM v2.3 User Manual; Centre for Water Research, University of Western Australia: Crawley, Australia, 2006.

23. Romero, J.; Antenucci, J.; Okley, P. Happy Valley Reservoir Modelling Study-Final Report; Centre for Water Research, University of Western Australia: Crawley, Australia, 2005; p. 41.

24. USCE. CE-QUAL-R1: A Numerical One-Dimensional Model of Reservoir Water Quality; User's Manual; Instruction Report E-82-1 (Revised Edition); Department of the Army, U.S. Corps Engineers: Washington, DC, USA, 1995; p. 427.

25. Krüger, G.H.J.; Eloff, J.N. The influence of light intensity on the growth of different Microcystis isolates. J. Limnol. Soc. South. Afr. 2010, 3, 21-25.

26. Coles, J.F.; Jones, R.C. Effect of temperature on photosynthesis-light response and growth of four phytoplankton species isolated from a tidal freshwater river. J. Phycol. 2000, 36, 7-16.

27. Schladow, S.; Hamilton, D. Prediction of water quality in lakes and reservoirs: Part II-Model calibration, sensitivity analysis and application. Ecol. Modell. 1997, 96, 111-123.

28. Hamilton, D.P.; Schladow, S.G. Prediction of water quality in lakes and reservoirs. Part I-Model description. Ecol. Model. 1997, 96, 91-110.

29. Griffin, S.L.; Herzfeld, M.; Hamilton, D.P. Modelling the impact of zooplankton grazing on phytoplankton biomass during a dinoflagellate bloom in the Swan River Estuary, Western Australia. Ecol. Eng. 2001, 16, 373-394.

30. Robarts, R.D.; Zohary, T. Temperature effects on photosynthetic capacity, respiration, and growth-rates of bloom-forming cyanobacteria. N. Z. J. Mar. Freshw. Res. 1987, 21, 391-399.

31. Elliott, J.A.; Jones, I.D.; Thackeray, S.J. Testing the sensitivity of phytoplankton communities to changes in water temperature and nutrient load, in a temperate lake. Hydrobiologia 2006, 559, 401-411.

32. Mooij, W.M.; Janse, J.H.; Senerpont Domis, L.N.; Hülsmann, S.; Ibelings, B.W. Predicting the effect of climate change on temperate shallow lakes with the ecosystem model PCLake. Hydrobiologia 2007, 584, 443-454.

(C) 2015 by the authors; licensee MDPI, Basel, Switzerland. This article is an open access article distributed under the terms and conditions of the Creative Commons Attribution license (http://creativecommons.org/licenses/by/4.0/). 